\title{
Practitioner Response to Onishi Paper
}

\section{S. Sanae Tokumura ACFRE, APR}

is fundraising and public relations consultant, and president of the firm Solid Concepts, Inc. in Honolulu, Hawaii. Sanae has worked in the fields of fund development and public relations for more than 25 years. An early interest in humanitarian concerns led Sanae from a news reporting career to assisting the community through the non-profit sector. Author and resource for numerous articles on fundraising, she has served on the International Association of Fundraising Professionals Foundation for Philanthropy Board and is past chair of the Advanced Certified Fundraising Executive Professional Certification Board.

International Journal of Educational Advancement (2007) 7, 226-228. doi:10.1057/palgrave.ijea.2150067

\section{The Globalization of Fundraising-In Our Backyard}

Our opportunity to advance our understanding of this concept presents itself not only overseas but also right here in our American backyard. In Hawaii where I work and in other larger metropolises in America, fundraising professionals eagerly face growing opportunities to involve diverse constituencies in the support of their organizations. Regarding Japanese support, whether from a Japan Japanese or American Japanese individual or corporation, there I have an advantage.

An American of Japanese ancestry, I am the product of three generations of American acculturation and assimilation in Hawaii's unique social environment. In a monograph entitled Fundraising mores in diverse communities: The role of ethnicity and culture, I identified myself "first as a Christian American mother with Buddhist values, second as a fundraiser, and, oh yes-a wife." Because of my background I understand the protocol of communicating with American Japanese of various generations, Japanese nationals of various ages, both male and female, and the Japanese corporation or small business. Many of my locally raised contemporaries in Hawaii, of Japanese ancestry or not, would probably understand the nuances of behavior and communication as well. In our youth, we grew up blind to most ethnic differences, and later learned to adjust our behaviors seamlessly as we encountered an ethnic rainbow of neighbors, friends, and family on a daily basis.

The innocent acceptance of playground differences and nurtured understanding of expectations followed us into our professional lives. Business and philanthropy in Hawaii is definitely conducted with an awareness of ethnic and racial differences; communication and behavior for the most part is adjusted respectfully.

Some practical tips for working with Japanese in pursuit of the major gift regardless of where your nonprofit may be based: 


\section{Japan Japanese}

1. Recruit Japanese volunteers or others in that social group; consider hiring development officers familiar with Japanese culture; recruit persons familiar with Japanese culture/business to your board; reflect how your programs may affect that constituency.

2. Utilize peers to initiate the prospect's interest in the organization's mission. Invite the prospect via peer to a discreet event. Get a small, meaningful gift to remind the prospect of this first encounter. Packaging is very important to the Japanese. This means: loud, gaudy is out, sophisticated, clean is in-some thought must be spent on what event and gift would be most appropriate that would both articulate your mission and reflect refinement.

3. Manners: Never, never be late. Be 15 minutes early. If visiting a home, be prepared to remove shoes. Greet in the traditional Japanese style: bow from the waist lower and longer than they do. Present your business card with two hands. Receive their business card (if offered) with two hands. Read it, comment on it, and then put it away in your wallet. Do not laugh too loud or make large motions; this is considered crude. Admire the surroundings and make small talk. Allow the prospect to speak more than you do. Do not attempt to speak in Japanese if you are not fluent.

4. In a later visit, when the prospect is familiar with the organization's mission and friendly with the organization according to peer counsel, it's time for the ask. Invite the prospect (and spouse) to a luncheon/dinner with the peer (who is already a donor); at least a CEO must be present or a chair of the board; brief presentation must be made; artful giving opportunity by peer or organization leader must be articulated.

5. Japan Japanese prospects should rarely be solicited by development officers or leaders who are lower socially than they. Always invite the spouse. Ideal presenters are the organization's CEO or board chair, or campaign chair, or celebrity volunteer. Older solicitors are better; male solicitors are better for Japan Japanese unless the top person in your organization is female. That top person should always be present in a major gift solicitation with a Japan Japanese prospect.

6. Japan Japanese are deeply motivated by duty and obligation to their personal ideals and friendships. Stories about the past and how their ancestors or family friends may have wanted them to support or continue their loyalty to a particular cause especially resonates with Japan Japanese.

\section{American Japanese}

1. There is likely to be untapped wealth in this part of American society. Many individuals prefer to save their money and invest for the sake of their children, the second and third generation, and beyond. Information about practical financial advantages for future generations using charitable giving is key. Academic education is a priority with this group as a whole.

2. Manners: American business manners are expected. Be prepared to remove shoes if visiting private homes. Habits vary. Whatever you do, don't bow or 
try to speak Japanese. These are Americans that look Japanese. By the third generation, most can't speak Japanese. Approach using peers; male or female is fine. Loud/brassy personalities should not approach.

3. First generation is mostly gone. Second and third generations are retired or planning their retirement. This is the patriotic generation-heroes of the 100th Battalion, the 442nd Regimental Combat Team, the Military Intelligence Service-and their sons and daughters who may be veterans of the Vietnam War. Some WWII families gave their only sons to war efforts as they waited hopefully for their return, imprisoned in American concentration camps. Approach with great respect for these sacrifices. Understand the fear and loathing they still have for the indignities and American prejudice they lived through during the prime of their American citizenship. Typically, the wealthy second or third American Japanese will want to know how their gifts can make an impact, may want to be involved in the organization's mission directly, and at least be given a full accounting of the outcome of their contributions, absolutely similar to this generation's non-Japanese peers.

4. Fourth- and fifth-generation American Japanese, like most ethnic groups of these generations, should be treated like any other prospective American millennial philanthropist. 